cancer: is a 'fighting spirit' coping style associated with longer survival times, or social support associated with lower mortality? However, these types of pathways are now considered too simple and misleading. Immune surveillance seems to be less important in the development of most types of solid tumours than previously thought, although the immune system is still thought to be very important in limiting tumour development and late-stage metastatic spread. The authors suggest that future researchers will need to develop new hypotheses for specific types of cancer. Therefore, despite an increase in our understanding of the bidirectional communications between the mind, the nervous system, the endocrine system, the immune system and the cancer, there seems to be more caution in linking psychological interventions to reductions in cancer mortality.

The important message of this book is that the mind is clearly important for cancer patients (as for all patients) and in the past few years psycho-oncology as a clinical discipline has grown and is increasingly seen as very relevant to clinical care. There is clear evidence that psychological interventions improve the quality of life for cancer patients, but the jury is still out on whether a better quality of life can lead to living longer. The book would have benefited from much more editing - the few psychological intervention studies testing the latter hypothesis were repeated too often and in too much detail. The critical reviews in each chapter provide useful summaries and this book would be much thumbed in a specialist library.

Louise Howard Research Fellow, Health Services Research Department, King's College London, P029, De Crespigny Park, Denmark Hill, London SE5 8AF, UK

\section{Principles and Practice of Geriatric Psychiatry (2nd edn)}

Edited by John R. M. Copeland, Mohammed T. Abou-Saleh \& Dan G. Blazer. Chichester: John Wiley \& Sons. 2002.809 pp. £275 (hb). ISBN 0 47। 981974

Why should anyone buy an extremely large textbook in these days of electronic publications, evidence-based reviews and so on? Well, many of us still take pleasure in owning and reading books, rather than extracting information from computer screens. However, we really have to be able to justify spending money on a large volume. In my view there is added value in reading this book. It is a scholarly volume of joint British and North American editorship containing chapters by most major international figures in old age psychiatry (although American and British authors predominate). An entire section is devoted to the development and organisation of old age psychiatry services in the UK and USA that could not be easily gleaned from reading a few papers. Despite what many of us perceive as the underfunding of UK services, it was reassuring to read that our services have not evolved from a privatepractice model or Medicare-style funding, neither of which appears to be geared to the complex community assessment and treatment needs of the majority of our patients.

It is impossible to do justice to the content of this volume in a few hundred words. In addition to the expected sections on psychiatric disorders, there are comprehensive collections of chapters on normal and abnormal ageing, diagnosis and assessment, and cross-cultural presentations. The final part of the book describes patterns of service and then moves to sections on rehabilitation, prevention and education. Individual chapters vary in their scope, but most are detailed and well referenced. For academics, there is a wealth of information from which lectures can be constructed.

Highlights are a very personal issue, reflecting perhaps my own interests and, more tellingly, areas of relative ignorance in which I felt I had learned something. There

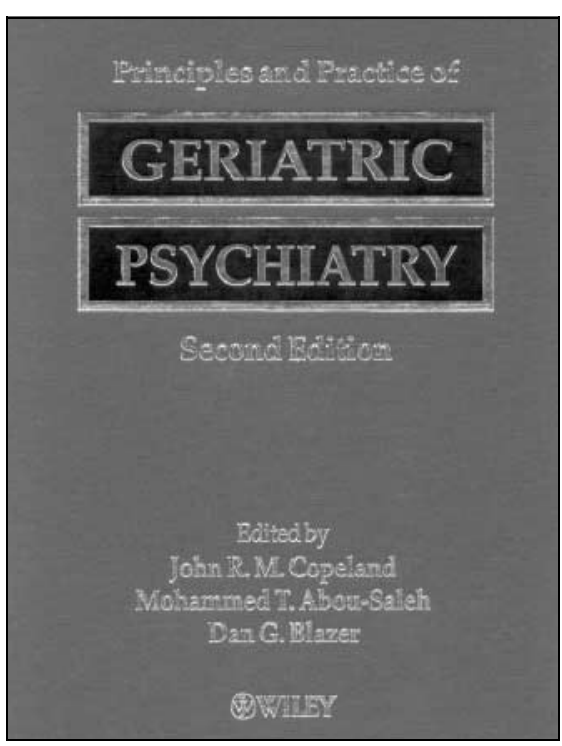

are many chapters covering clinically complex areas of practice. However, I particularly enjoyed reading two rather unusual ones. The first is a chapter by Seymour on the effect of anaesthetics on mental state. This includes a description of the mechanisms by which cognitive change occurs, details of an international study of postoperative cognitive dysfunction and a table summarising the findings of comparisons of general anaesthesia and regional anaesthesia on mental function. This wealth of information is not generally easily accessible to old age psychiatrists. The second is a damning analysis of UK law and the rights of elderly people by Edwards. He argues that UK law allows extensive abuse of elderly people's rights, with those working with the elderly often unaware of what the law does and does not permit. Statute law takes precedence over common law, but the latter is often used instead of a guardianship order to detain someone in a residential or nursing home. Practices such as these could well be challenged under the Human Rights Act 1998.

The editors have chosen their authors well, and most chapters are eclectically written. There is inevitably overlap of information, and a few of the brief contributions could have been incorporated into larger core chapters. This is a minor point and it does not detract from the overall high quality of a book that I thoroughly recommend to individuals and departments.

J. L. Herzberg Consultant Old Age Psychiatrist and Honorary Senior Clinical Lecturer, The Royal London Hospital (Mile End), Bancroft Road, London El 4DG, UK

\section{Stress and the Heart. Psychosocial Pathways to Coronary Heart Disease}

Edited by Stephen A. Stansfeld

\& Michael G. Marmot. London: BMJ Books. 2002. 315 pp. $€ 30.00$ (pb). ISBN 07279 I277 I

I recall a moment in 1984 when my MD supervisor, the late Professor Robert Cawley, questioned my interest in type A behaviour, which was considered at the time to be a key psychosocial risk factor for coronary heart disease. 'I do not think that will lead anywhere, my boy', he opined, and his prescient remarks were borne out 